\title{
Microwave-Assisted Synthesis of Ag/Cu Bimetallic Nanoparticles And Their Antibacterial Properties
}

\author{
Pei-Yi LI ${ }^{1,2}$, Shu-Peng SONG ${ }^{1,2, *}$, He-Rong ZHOU ${ }^{1}$, Yuan-Zhuo ZHANG ${ }^{1}$, Tian \\ WAN $^{1}$
}

${ }^{1}$ State Key Laboratory of Refractories and Metallurgy, Wuhan University of Science and Technology, Wuhan, 430081, People's Republic of China

${ }^{2}$ Department of Materials and Metallurgy, Wuhan University of Science and Technology, Wuhan, 430081, People's Republic of China

spsong@wust.edu.cn

*correspondent author

Keywords: Ag/Cu bimetallic nanoparticles, Microwave-assisted heating, Antibacterial properties

\begin{abstract}
Ag} / \mathrm{Cu}$ bimetallic nanoparticles were synthesised in a few minutes using 1-heptanol as reducing agent in a microwave reactor. The products of microwave heating and oil-bath heating were compared. Experimental results decide that, it is easier to obtain a higher degree of crystallization, smaller size distribution particles under microwave heating than oil-bath heating. And the products obtained by microwave heating method showed good antibacterial performance against Escherichia coli.
\end{abstract}

\section{Introduction}

Due to the novel optical, electronic, magnetic and catalytic properties, intensive attention has been attracted by bimetallic nanoparticles [1-3]. Various preparation methods of bimetallic nanoparticles were developed. The sol-gel method, hydrothermal method, polyol method, colloidal particle seeding method, displacement method, co-precipitation method, electrochemical method have been widely used in the synthesis of stable bimetallic nanomaterials [4-6].

For the rapid synthesis of bimetallic nanoparticles, microwave dielectric heating has been developed. Traditional heating methods inevitably effect by temperature gradient, which causes uneven heating. When materials are under microwave irradiation, high frequency reciprocating motion of the dipolar molecules generates energy by molecular friction to heat up the materials. Interior and exterior of the materials are heated at the same time. And the materials are heated quickly and uniform [7-9]. In this work, we used microwave reactor to synthesis $\mathrm{Ag} / \mathrm{Cu}$ bimetallic nanoparticles. The products were in various shapes and well-distributed. And the antibacterial properties of the nanoparticles were tested.

\section{Experimental}

\section{Chemicals}

$\mathrm{AgNO}_{3}(99.8 \%, \mathrm{AR}), \mathrm{Cu}\left(\mathrm{CH}_{3} \mathrm{COO}\right)_{2} \cdot \mathrm{H}_{2} \mathrm{O}(99.0 \%$, $\mathrm{AR})$ and 1-heptanol (99.0\%, AR) were purchased from Aladdin Co. (Shanghai, China). Polyvinylpyrrolidone (PVP, Mw=30000, GR) and $\mathrm{CH}_{3} \mathrm{COOH}$ (AR) were purchased from Sinopharm Chemical Reagent Co. , Ltd. (Shanghai, China).

\section{Preparation of PVP-protected Ag/Cu Nanoparticles}

In a typical synthesis of Ag nanoparticles, $10 \mathrm{~mL}$ of $6 \mathrm{mM} \mathrm{AgNO}_{3}$ in 1-heptanol and $5 \mathrm{wt} \%$ PVP were mixed and dissolved in a flask. Then put the mixture in the microwave reactor at $176{ }^{\circ} \mathrm{C}$ for 2 min to prepare Ag nanoparticles. Model of the Microwave reactor was WBFY-201, full power of the Microwave reactor was $650 \mathrm{~W}$, and the frequency was $2450 \pm 50 \mathrm{MHz}$. Then $10 \mathrm{~mL}$ of $12 \mathrm{mM} \mathrm{Cu}$ 
$\left(\mathrm{CH}_{3} \mathrm{COO}\right)_{2} \cdot \mathrm{H}_{2} \mathrm{O}$ was added to the above solution. Finally put the solution in the microwave reactor and maintained at $176{ }^{\circ} \mathrm{C}$ for 2 min to prepare $\mathrm{Ag} / \mathrm{Cu}$ bimetallic nanoparticles.

To synthesis a sample for comparison, the similar steps were taken. Thus, we used oil-bath heating instead of microwave heating. The same amount as above of $\mathrm{AgNO}_{3}, \mathrm{PVP}$ and 1-heptanol were dissolved in a flask. The solution was maintained at $176^{\circ} \mathrm{C}$ under oil-bath heating for $20 \mathrm{~min}$. Then 10 $\mathrm{mL}$ of $12 \mathrm{mM}$ of $\mathrm{Cu}\left(\mathrm{CH}_{3} \mathrm{COO}\right)_{2} \cdot \mathrm{H}_{2} \mathrm{O}$ was added to the above solution. The mixture was maintained at $176^{\circ} \mathrm{C}$ under oil-bath heating for $20 \mathrm{~min}$.

Both of the product solutions were centrifuged three times at the speed of 15,000 rpm, 15 min for each time. Model of the centrifuge was H1850. The maximal speed of the centrifuge was 18,000 rpm. The final precipitates were extracted and dispersed in deionized water.

\section{Characterization and Instruments}

Nanoparticles were characterized by X'Pert PRO MPD X-ray diffractometer with $\mathrm{Cu}$ K $\alpha$ radiation $(\lambda$ $=1.54056 \AA$ ). The scanning rate was $2 \% \mathrm{~min}$. Morphology of these nanoparticles was characterized by transmission electron microscopy (TEM, FEI-G20). TEM samples were prepared by dropping colloidal solutions of $\mathrm{Ag} / \mathrm{Cu}$ nanoparticles onto carbon-coated $\mathrm{Cu}$ grids. Antibacterial activity of nanoparticles was measured by filtering paper method. The $6 \mathrm{~mm}$ diameter filter papers were soaked in the nanoparticle solutions. Then put them onto the solid mediums which Escherichia coli have incubated in. Concentration of Escherichia coli was $10^{8} \mathrm{cfu} / \mathrm{mL}$. Finally, these mediums were maintained at $37^{\circ} \mathrm{C}$ in a constant incubator for 24 hours.

\section{Results and Discussion}

\section{Characterization of the Ag/Cu Nanoparticles}

Fig. 1 shows a typical XRD pattern of the products which were synthesised by microwave-assisted method. The Four peaks in the pattern located at $38.26^{\circ}, 44.38^{\circ}, 64.67^{\circ}$, and $77.54^{\circ}$ can be indexed to the (111), (200), (220) and (311) planes of face-centered cubic Ag. The other three peaks located at $43.55^{\circ}, 50.57^{\circ}$ and $74.23^{\circ}$ are assigned to the (111), (200) and (220) diffraction planes of the face-centered cubic $\mathrm{Cu}$. This indicates that the synthesised nanoparticles via microwave-assisted method are composed of silver and copper. There are no other obvious peaks in Fig. 1, indicating that other impurities such as $\mathrm{CuO}$ were not produced. The nanoparticles were completely composed of face-centered cubic Ag and $\mathrm{Cu}$.

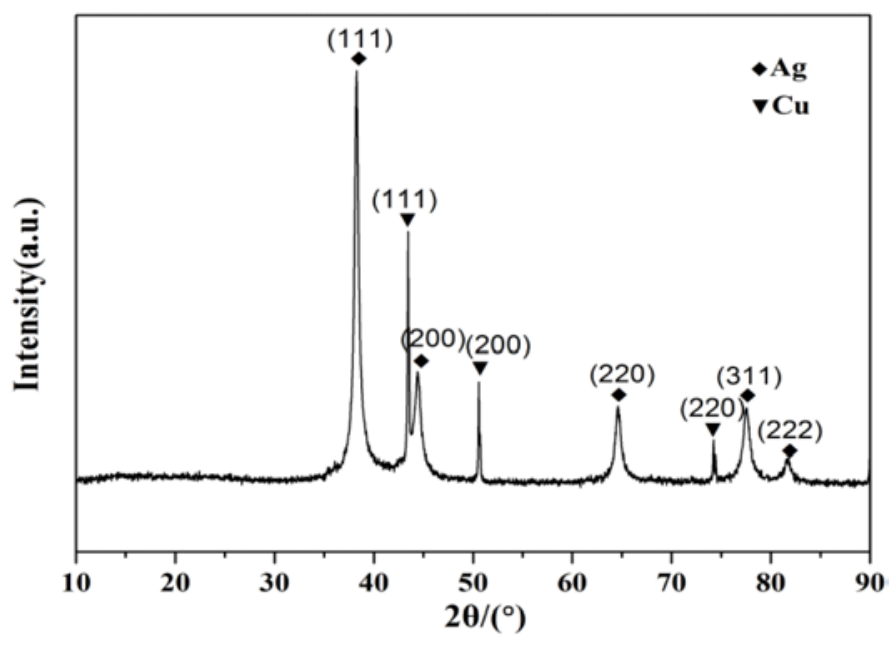

Fig. 1 XRD patterns of Ag/Cu bimetallic nanoparticles

Fig. 2 (a)-(d) are the typical TEM images of Ag/Cu nanoparticles. Fig. 2 (a) and (b) are the TEM images of the product obtained by microwave heating. Fig. 2 (a) showed different shapes of Ag/Cu nanoparticles, including triangle, pentagon, hexagon, spherical, cylindrical and other polyhedrons. 
Fig. 2 (b) showed the typical triangle and hexagon nanoparticles. From Fig. 2 (a) and (b), it was determined that the particle sizes were $20 \sim 80 \mathrm{~nm}$. All particles distributed uniformly without aggregation under the protection of PVP. Fig. 2 (c) and (d) showed morphology of the oil-bath heating product. The particle sizes range from $10 \sim 150 \mathrm{~nm}$. From Fig. 2 (c), it can be observed that the particles clumped together and the majority of the particles were spherical. Fig. 2 (d) showed that the particles were in a range of sizes without definite shapes.
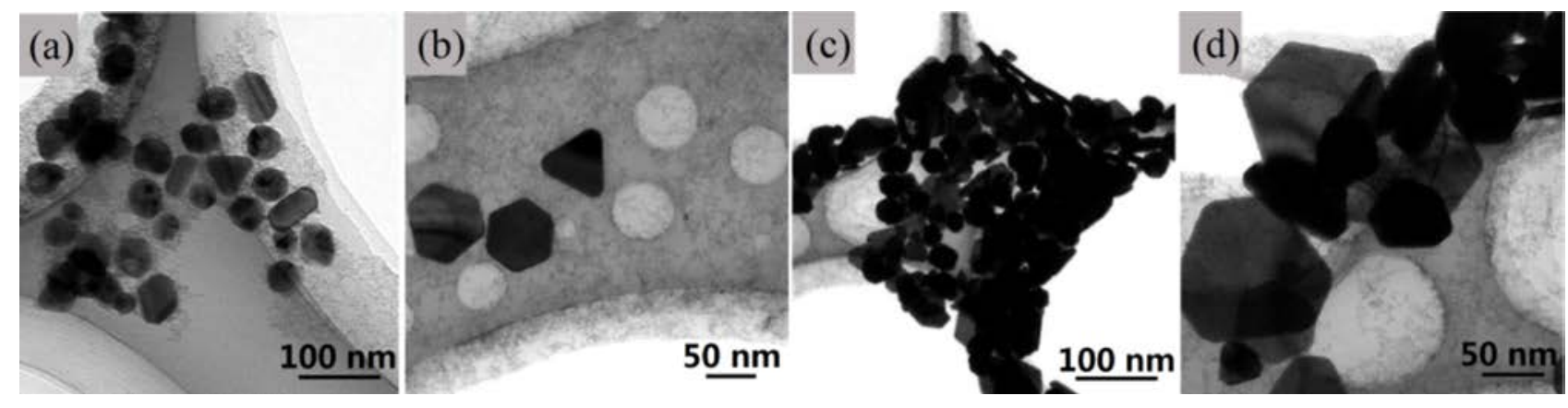

Fig. 2 TEM images of Ag/Cu nanoparticles. (a) different shapes of nanoparticles prepared by MW heating, (b) typical triangle and hexagon nanoparticles prepared by MW heating, (c) nanoparticles prepared by oil-bath heating, (d)irregular shapes of nanoparticles prepared by oil-bath heating.

Fig. 3 is the selected area electron diffraction (SAED) pattern of Ag/Cu nanoparticles prepared by microwave heating. The diffraction spots and rings at different places correspond to (111), (200), and (220) facets and other facets of $\mathrm{Ag}$ and $\mathrm{Cu}$, respectively. The synthesised elemental $\mathrm{Ag}$ and $\mathrm{Cu}$ are face-centered cubic structure and their lattice constants are very close. The lattice constants of Ag and $\mathrm{Cu}$ are respectively $0.409 \mathrm{~nm}$ and $0.361 \mathrm{~nm}$, making it possibble to synthesis $\mathrm{Ag} / \mathrm{Cu}$ bimetallic nanoparticles [10]. The standard redox potential of $\mathrm{Cu}^{2+} / \mathrm{Cu}$ pair $(+0.34 \mathrm{eV})$ is lower than $\mathrm{Ag}^{+} / \mathrm{Ag}^{2}$ pair $(+0.78 \mathrm{eV})$. Therefore, the reduction of $\mathrm{Cu}^{2+}$ is slowly than $\mathrm{Ag}^{+}$. Thus, the diffraction contrast of diffraction rings of $\mathrm{Ag}$ is more obvious than $\mathrm{Cu}$ [11]. Based on these results, we can draw the conclusion that $\mathrm{Ag} / \mathrm{Cu}$ nanoparticles are face-centered cubic crystal structure instead of amorphous structure.

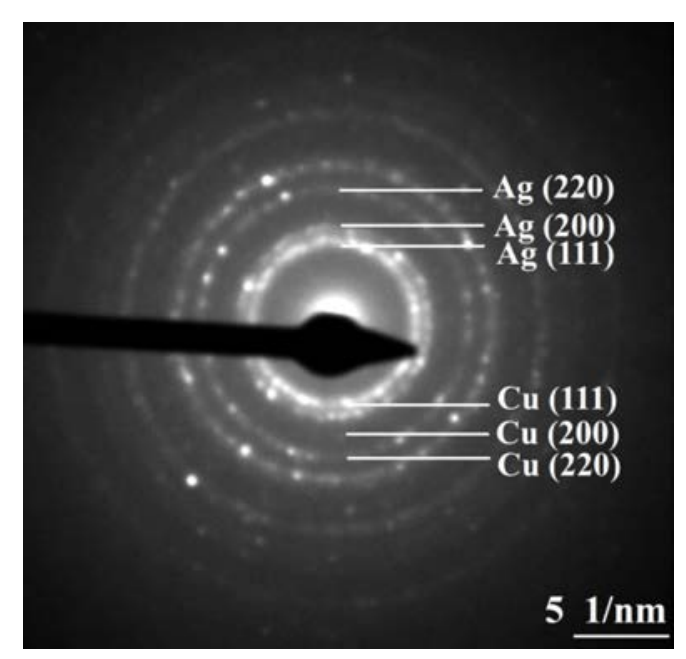

Fig. 3 SAED pattern of Ag/Cu bimetallic nanoparticles.

\section{Antibacterial properties of the Ag/Cu Nanoparticles}

Fig. 4 shows the antibacterial activity of $\mathrm{Ag} / \mathrm{Cu}$ nanoparticles against Escherichia coli. Marks A, B and $\mathrm{C}$ on filter paper were soaked in nano-sol prepared by microwave heating, while marks on filter 
paper D, E and F were soaked in nano-sol prepared by oil-bath heating, respectively. Mark G was soaked in deionized water to make a contrast. After 24 hours, there were clear bacteriostasis circles around A-F filter papers. However, no bacteriostasis circle can be observed around the G filter paper. This indicates that $\mathrm{Ag} / \mathrm{Cu}$ nanoparticles we synthsised have antibacterial properties. The diameters of bacteriostasis circles of A, B and C were $8.9 \mathrm{~mm}, 8.5 \mathrm{~mm}$ and $9.2 \mathrm{~mm}$, respectively. While the diameters of D, E and F were $7.9 \mathrm{~mm}, 8.2 \mathrm{~mm}$ and $8.0 \mathrm{~mm}$. The bacteriostasis circles of A, B and C were larger than $\mathrm{D}, \mathrm{E}$, and $\mathrm{F}$, indicating that the nano-sol prepared by microwave have better antibacterial activity. This can be explained by smaller sizes and uniform distribution of the nanoparticles prepared by microwave heating.

The antibacterial mechanism of metal nano-materials has been reported by previous researchers. Silver in $\mathrm{Cu} / \mathrm{Ag}$ bimetallic particles exists in the form of free element. The specific surface area of nanoparticles is extremely large. The surface atoms have a very high activity and extremely unstable. Silver nanoparticles can activate the oxygen in water and air, producing reactive oxygen species of strong oxidation. This may make cellular enzymes of the bacteria loss activity and destroy the permeability of cell membrane, resulting in the death of bacteria [12,13]. Therefore, silver nanoparticles can be used as antibacterial agent. Nano-copper can be combined with the DNA of microorganisms to prevent bacterial replication and destroy the metabolic enzymes, which leads to the loss of bacteria activity [14]. Thus $\mathrm{Ag} / \mathrm{Cu}$ alloy nanoparticles theoretically have excellent antibacterial performance due to the synergy of nano-copper and nano-silver.

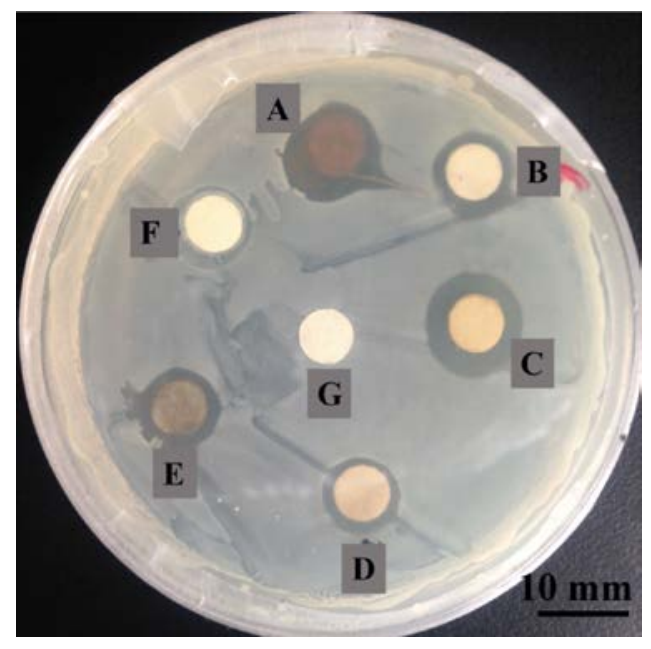

Fig. 4 Antibacterial activity of Ag/Cu nanoparticles against Escherichia coli.

Mark A-C: soaked in nano-sol prepared by microwave heating, average diameter $8.8 \mathrm{~mm}$, Mark D-F: soaked in nano-sol prepared by oil-bath heating, average diameter $8.0 \mathrm{~mm}$, Mark G: soaked in deionized water, diameter $6.0 \mathrm{~mm}$.

\section{Summary}

With silver nitrate and copper acetate as precursors, 1-heptanol as a reducing agent and PVP as protection agent, we have synthesised $\mathrm{Ag} / \mathrm{Cu}$ bimetallic nanoparticles by microwave-assisted heating method at $176{ }^{\circ} \mathbf{C}$. Compared to the product of oil-bath heating, the $\mathrm{Ag} / \mathrm{Cu}$ bimetallic nanoparticles have smaller sizes (20 80nm), various shapes, narrower size distribution, and distribute more evenly without aggregation.

Using filter paper method to detect the antibacterial performance of $\mathrm{Ag} / \mathrm{Cu}$ bimetallic nanoparticles, there were obvious inhibition zones, demonstrating that the bimetallic nanoparticles have good antibacterial properties. 


\section{Acknowledgements}

This work is financially co-supported by National Nature Science Foundation of China (50901053), Nature Science Foundation of Hubei Province (2014CFB799), Foundation of State Key Laboratory of Refractories and Metallurgy (2014QN19).

\section{References}

[1] W. Zhang, J. Yang, X. Lu, ACS Nano. , 2012, 8: 7397-7405.

[2] M. A. Mahmoud and M. A. EI-Sayed, Langmuir, 2012, 28: 4051-4059.

[3] Y. W. Lee, M. Kim, Z. H. Kim, S. W. Han, J. Am. Chem. Soc. , 2009, 131(47) : 17036-17037.

[4] K. Hirakawa, N. Toshima, Chem. Lett. , 2003, 32: 78.

[5] H. Zhang, T. Watanabe, M Okumura, M. Haruta, N. Toshima, Nat. Mater. , 2012, 11: 49-52.

[6] V. Udumula, J. H. Tyler, D. A. Davis, H. Wang, M. R. Linford, P. S. Minson, D. J. Michealis, ACS Catal. , 2015, 5 (6) : 3457-3462.

[7] T. Sumi, R. Dillert, S. Horikoshi, RSC Adv. , 2015, 5: 14637.

[8] Z. Chen, D. Mochizuki, M. M. Maitani, Y. Wada, Nanotech. , 2013, 24: 265602-265610.

[9] M. Tsuji, M. Hashimoto, Y. Nishizawa, M. Kubokawa, T. Tsuji, Chem. Eur. J. 2005, 11: 440-452.

[10] M. Valodkar, S. Modi, A Pal, S. Thakore, Mat. Res. Bull. , 2011: 384-389.

[11] M. Tsuj, S. Hikino, R. Tanabe, D. Yamaguchi, Chem. Lett. , 2010, 39: 334-336.

[12] G. A. Sotirious, S. E. Pratsinis, Environ. Sci. Technol. , 2010, 44 (14): 5649-5654.

[13] L. Rizzello, P. P. Pompa, Chem. Soc. Rev. , 2014, 43: 1501-1518.

[14] J. A. Limire, J. J. Harrison, R. J. Turner. Nat. Rev. Microbiol. , 2013, 11: 371-384. 